for latent TB in selected cases. We are the only unit in UK to have used this regimen.

The prevalence rate of latent $\mathrm{TB}$ was higher than anticipated at $15 \%$. Identifying active $\mathrm{TB}$ cases further demonstrated that this is a group worth targeting. These preliminary results led to an extension of this project.

\section{ACCESS TO GUM CLINICS IN THE UK - A WORSENING PICTURE?}

Tim Prescott*, Vanessa Hayden, Elizabeth Foley. University of Southampton, Southampton, UK

\subsection{6/sextrans-2015-052126.16}

Background/introduction In 2004 the Department of Health introduced a mandatory target for $100 \%$ of all patients in England to be offered 48-hour appointments by 2008. In 2010 these targets were removed and in April 2013 further changes to healthcare provision were introduced, with local authorities commissioning GUM (genitourinary medicine) services.

Aim(s)/objectives To assess the effect of recent commissioning changes to the accessibility to GUM clinics.

Methods During November 2014 male and female researchers telephoned all UK GUM clinics that were open for more than one day per week. Researchers contacted clinics twice: firstly presenting with symptoms consistent with an acute sexually transmitted infection and secondly requesting an appointment for an asymptomatic screen.

Results Of 236 clinics contacted, 89\% could accommodate symptomatic 'patients' within $48 \mathrm{~h}$ with $53 \%$ of these on a walk-in basis only. Suggested waiting times ranged between 20 min and $3 \mathrm{~h} .20 \%$ of asymptomatic 'patients' were unable to book an appointment and 58\% of appointments were offered within 48 h. $86 \%$ of asymptomatic 'patients' were offered either a walk in service or appointment within $48 \mathrm{~h}$.

Discussion/conclusion Overall $88 \%$ of 'patients' could be offered a time to be seen in a GUM clinic within $48 \mathrm{~h}$, lower than last year's figure of $95 \%$ and the BASHH standard of $98 \%$, suggesting service access has deteriorated. Further work will include a postal questionnaire to lead clinicians to evaluate their expectations on service access and visits to $33 \%$ of GUM clinics to explore the relationship between suggested waiting times and reality.

\section{WHEN'S BEST TO TEXT? OPTIMUM TIMING OF SMS APPOINTMENT REMINDERS}

Caroline Williams*, Luke Gregory, Ade Apoola, Hayley Wood. Derby Hospitals NHS Foundation Trust, Derby, UK

10.1136/sextrans-2015-052126.17
Background/introduction Throughout healthcare settings 'did not attend' (DNA) rates impact heavily on service efficacy and are estimated to cost the NHS $£ 600 \mathrm{~m}$ per year. Short message service (SMS) texts have been shown to reduce the DNA rates amongst Sexual Health patients.

Aim(s)/objectives The aim of this project was to assess the optimum timing of SMS appointment reminders and its impact on the non-attendance rates in our HIV and Sexual Health service. Methods For three consecutive four week periods between 30/ $12 / 2013$ and $06 / 04 / 2014$, in addition to the routine 'on the day' SMS reminder an extra reminder was sent 1,2 or 3 days prior to patient appointments. Data was collected concerning patient attendances during these periods for pre-booked appointments for HIV and Sexual Health patients. Statistical significance was calculated using Fisher's Exact test and Pearson's correlation coefficient as appropriate.

Results Attendance was monitored for 1,271, 1,215 and 1,264 patients in each 4 week group respectively. Amongst HIV patients, DNA rates fell as the time increased between the appointment and sending the extra SMS reminder. For Sexual Health patients, DNA rates fell as the time was decreased between the appointment and the extra SMS reminder. For both patient groups the gradient of this fall was statistically significant.

Discussion/conclusion This small project has demonstrated the optimum timing of SMS reminders appears different for HIV and Sexual Health patients. HIV patients had lower DNA rates when texted further from the appointment time, whereas Sexual Health patients DNA'd less often if texted nearer to their appointment. Further work is needed confirm the generalisability of our findings and reasons underpinning them.

\section{USE OF A NOVEL QUEUE MANAGEMENT SOFTWARE PROGRAM TO IMPROVE PATIENT SATISFACTION AT A LARGE URBAN GUM CLINIC}

Martina Toby, Cindy Sethi, Anatole Menon-Johansson*. Guys and St Thomas' NHS Foundation Trust, London, UK

\subsection{6/sextrans-2015-052126.18}

Background/introduction Since opening a new clinic there has been high patient flow particularly at weekends. Even with adequate staffing and patients performing self-triage, waiting times sometimes exceed three hours. This frequently resulted in patient aggression towards reception staff, poor patient feedback about waiting times and staff complaints with incident reporting forms (IR1). In October 2014 - new software was introduced to improve patient satisfaction.

Methods Upon entry to the clinic all symptomatic patients were registered on the program which automatically sent a text message informing them of their place in the queue. They were then

\begin{tabular}{|c|c|c|c|c|c|c|c|}
\hline & $\begin{array}{l}\text { DNA Rate SMS sent } \\
1 \text { day prior to } \\
\text { appointment }\end{array}$ & $\begin{array}{l}\text { DNA Rate SMS sent } \\
2 \text { days prior to } \\
\text { appointment }\end{array}$ & $\begin{array}{l}\text { DNA Rate SMS sent } \\
3 \text { days prior to } \\
\text { appointment }\end{array}$ & $\begin{array}{l}1 \text { vs } 2 \text { days } \\
\text { (p) }\end{array}$ & $\begin{array}{l}1 \text { vs } 3 \text { days } \\
\text { (p) }\end{array}$ & $\begin{array}{l}2 \text { vs } 3 \text { days } \\
\text { (p) }\end{array}$ & $\begin{array}{l}\text { Correlation } \\
\text { coefficient } \\
\text { (p) }\end{array}$ \\
\hline HIV Patients & $16.60 \%$ & $16.30 \%$ & $10.24 \%$ & 1.0000 & 0.0483 & 0.0534 & 0.042 \\
\hline Sexual Health Patients & $8.26 \%$ & $9.96 \%$ & $11.16 \%$ & 0.1609 & 0.0167 & 0.3665 & 0.014 \\
\hline
\end{tabular}


invited by reception staff to leave the clinic until they were sent another text when they were due to be seen. Patients in possession of a Smartphone could refresh a link to check their place in the queue at any time. IR1s and patient feedback were assessed before and after implementation

Results Average no of symptomatic patients seen over a weekend was 70 with an average wait time of 89 min. In the 4 month period prior to the software implementation there were 6 IR1 forms received from staff about patient aggression. In the 4 month period after its introduction there were none. Two months post its introduction the average number of patient complaints about waiting times received was 1 from an average of 4 prior to its use.

Conclusion The introduction of the queuing software has been an inexpensive and effective method of reducing complaints about patient waiting times and improving patient satisfaction with the service.

\section{CAN EXPRESS TREATMENT REDUCE ONWARD TRANSMISSION?}

Ruth Byrne*, Farhad Cooper, Tim Appleby, Leigh Chislett, Lucy Freeman, Elizabeth Kershaw, Nneka Nwokolo, Gary Whitlock, Alan Mcowan. Chelsea and Westminster Hospital, London, UK

\subsection{6/sextrans-2015-052126.19}

Background/introduction The introduction of onsite Cepheid ${ }^{\circledR}$ GeneXpert diagnostics for asymptomatic STI screens cut 'test to treatment' time by $190 \mathrm{~h}$.

Aim(s)/objectives To evaluate the Public Health benefit of faster treatment.

Methods Patients with chlamydia (CT) and/or gonorrhoea (GC) over 8 weeks in February 2014 were retrospectively identified. We compared the timing of testing, treatment and number of recent sexual partners with a control group from November 2013. Assuming rate of partners remains unchanged, we calculated 'partners spared' exposure per infected patient due to faster treatment.

Results 431 patients were identified with CT and/or GC infection. 81\% (349/431) were MSM. Median age was 29 years. $23 \%$ of index patients disclosed high risk behaviour including fisting, chemsex and injecting drug use. Median 'test to treatment' time dropped from $238 \mathrm{~h}$ to $48 \mathrm{~h}$. The number of partners spared exposure was 0.5 per index case. This equates to a total 196 partners spared exposure over the study period.

Discussion/conclusion For every two people diagnosed with an infection, one partner was spared exposure. Limiting the duration of infectivity and the potential for onward transmission has clear public health benefits and is of particular value in this cohort with multiple partners who engage in high-risk behaviour.

\section{O20 ON-LINE STI TESTING SERVICES: IMPROVING ACCESS, EFFICIENCY AND USER EXPERIENCE}

${ }^{1}$ Michael Brady ${ }^{*},{ }^{2}$ Chris Howroyd, ${ }^{2}$ Glyn Parry, ${ }^{1,2}$ Paula Baraitser, ${ }^{2,3}$ Gillian Holdsworth, ${ }^{4}$ Anatole Menon-Johansson. 'Kings College Hospital NHS Foundation Trust, London, Norway; ${ }^{2}$ SH:24, London, UK; ${ }^{3}$ Lambeth and Southwark Public Health Department, London, UK; ${ }^{4}$ Guys and St Thomas' NHS Foundation Trust, London, UK

10.1136/sextrans-2015-052126.20
Background/introduction There are many barriers to accessing sexual health and HIV testing services. Novel service models could address this. On-line testing may provide a solution.

Aim(s)/objectives To evaluate the acceptability and potential impact of on-line STI testing.

Methods We developed a dedicated, secure website for free online STI testing. Website content and testing process was iteratively designed in response to user feedback. Simple questions identify those most at risk or symptomatic and signpost to local services. Clients order self-taken NAAT tests for chlamydia (CT) and gonorrhoea (GC) and a pin-prick blood test for syphilis and $4^{\text {th }}$ generation HIV testing and post them to the laboratory. Results are received by text. In November 2014 we piloted the process by offering it to clients attending 2 sexual health services.

Results 47 clients used the service. 31 (65.9\%) men, of whom 5 (16\%) were MSM. Mean age was 29 (range 19-64). Mean time to receipt of results was 3 days (range 0-8). 18 (38.3\%) clients received their results on the same day the sample was taken. One client tested positive for syphilis. All other tests were negative. User feedback was predominantly positive, with specific reference to its speed and simplicity. $8 / 47$ (17\%) left negative feedback about the pinprick process, which they found difficult or unpleasant.

Discussion/conclusion The service was highly acceptable. Rapid results turnaround was more efficient than local 'traditional' services. The service (which soon becomes available to all local residents) will contribute significantly to local STI/HIV testing and prevention strategies.

\section{SECURING EXCELLENCE IN CHLAMYDIA SCREENING OUTCOMES ON A SHRINKING BUDGET}

${ }^{1}$ Sharon Foster, ${ }^{1}$ Victoria Womack, ${ }^{2}$ Sharron Ainslie, ${ }^{2}$ Kate A Folkard, ${ }^{2}$ Kevin Dunbar, ${ }^{2}$ John Saunders*. 'Leeds City Council, Leeds, UK; ${ }^{2}$ Public Health England, London, UK

\subsection{6/sextrans-2015-052126.21}

Background/introduction The National Chlamydia Screening Programme (NCSP) recommends opportunistically screening sexually active 15 to 24 year olds annually and on change of partner. Through a number of changes to the delivery of screening, Leeds has maintained a higher than average detection rate indicator (DRI) despite declining spend. We describe these changes and corresponding DRIs.

Aim(s)/objectives To review and re-structure chlamydia control activity to provide greater value for money.

Methods A multi-professional steering group was established and a strategic approach taken to commission chlamydia within sexual health services. Our approach included: screening, treatment and partner notification embedded within contraception and sexual health services; commissioning of online testing and an enhanced pharmacy scheme; signposting website developed; phasing out financial incentives for General Practitioners (GP); reducing outreach testing, marketing and staff.

Results In $2014 £ 371 \mathrm{k}$ was spent on screening activities $(£ 538 \mathrm{k}$ 2010/11). 2014 Q1-Q2 DRI was 3,104 (2,168 England; 2,325 Yorkshire and Humber) and 2,511 (1,888 England; 2,128 Y\&H), respectively compared to 2,698 (2,093 England; 2,367 $\mathrm{Y} \& \mathrm{H})$ and 2,355 (1,947 England; 2,068 Y\&H) for equivalent time periods in 2013. In 2013 most tests were performed in GP (30\%) followed by GUM (26.6\%), Internet (26.8\%) and CASH (13.5\%). Positivity across all settings in 2013 was $9.5 \%$. 